\title{
Evaluation Alternative Tourism of Bingol (Turkey)
}

\author{
Omer Kilic (Corresponding author) \\ Adiyaman University, Pharmacy Faculty, Adiyaman, Turkey. \\ E-mail: omerkilic77@gmail.com \\ Zeyneb Kilic \\ Adiyaman University, Engineering Faculty, \\ Department of Civil Engineering, Adiyaman, Turkey.
}

\begin{abstract}
Alternative tourism is a type of tourism that provides cultural interaction and income to the local people in the area where it is realized and is now included in the rural development policies of many countries and supported in development strategies. Bingöl city has rich vegetation, natural beauty, various nature tourism (plateau-flora-winter-river-hunting-cave, wildlife observation and trekking) activities in terms of rural tourism, so Bingöl has a separate place about potential turism activities. Therefore, the heritage, natural beauties and rural tourism potential of Bingöl should be promoted in a more remarkable and awareness-raising manner and tourism activities in the province should be supported more and potential should be realized. In this study, the literature review, field studies and observations, the concept of rural tourism and the importance of rural tourism are tried to be explained and the existing rural tourism potential of Bingöl province is evaluated with observations and visual materials. The living standards of the local people will be further improved by increasing the tourism and natural values, agricultural and cultural activities, thus contributing to the development of the Bingöl city.
\end{abstract}

Keywords: Bingöl, tourism, alternarive tourism, rural tourism.

DOI: $10.7176 / J S T R / 5-12-32$

\section{Bingöl’ün (Türkiye) Alternatif Turizm Açısından Değerlendirilmesi}

\begin{abstract}
Özet
Alternatif turizm, gerçekleştirildiği alanda kültürel etkileşimi sağlayan ve yöre halkına gelir getiren bir turizm çeşidi olup, günümüzde birçok ülkenin kırsal kalkınma politikalarında yer almakta ve kalkınma stratejilerinde desteklenmektedir. Zengin bitki örtüsü, doğal güzellikleri, çeşitli doğa turizmi (yaylaflorakış-akarsu-av-mağara gibi turizm alanlarının olması, yaban hayatı gözlemciliği ve doğa yürüyüşü) etkinliklerinin olması Bingöl'ün kırsal turizm açısından ülkemizde ayrı bir yeri olduğunun ve bu konudaki potansiyelinin göstergeleridir. Dolayısıyla Bingöl'ün sahip olduğu miraslar, doğal güzellikleri, kırsal turizm potansiyeli daha dikkat çekici ve farkındalık oluşturucu şekilde tanıtılmalı ve ildeki turizm faaliyetleri daha fazla desteklenmeli ve bu zengin potansiyelin ortaya çıkması sağlanmalıdır. Bu çalışmada, yapılan literatür taraması, arazi çalışmaları ve gözlemler ile kırsal turizm kavramı ve kırsal turizmin önemi anlatılmaya çalışılıış ve ele alınan konu çerçevesinde Bingöl ilinin mevcut kırsal turizm potansiyeli gözlemle ve görsel materyallerle değerlendirilmiştir. Bingöl'de kırsal alanlardaki turistik ile doğal değerlerin, tarımsal ve kültürel etkinliklerin arttırılması ve tanıtılması ile yöre halkının yaşam standartları daha da iyileşecek ve böylece ilin kalkınmasına da katkı sağlanacaktır.
\end{abstract}

Anahtar Kelimeler: Bingöl, turizm, alternatif turizm, kırsal turizm. 


\section{Giriş}

Turizm hem ulusal ekonomiye katkıda bulunan hem de uluslararası kültürel ve toplumsal iletişimi sağlayıcı, ekonomik sorunların aşılmasında yardımcı ve bütünleştirici etkisi ile dünya barışının korunmasında büyük payı olan bir sektördür (Akar \& Karamanbüyük, 2006). Turizm faaliyetlerin en önemli ve en etkili sonuçlarından biri ülke ve gerçekleştiği çevreye önemli ölçüde gelir getirici bir özelliğe sahip olmasıdır. Özellikle daha fazla kalkınmak isteyen Bingöl gibi illerin karşılaştığı ekonomik güçlüklerin aşılmasında turizm gelirlerine duyulan ihtiyaç her geçen gün artmaktadır. Turizm, gelirleri yatırım malları ithalinin gerektirdiği dövizin sağlanmasında, ticaret dengesi açıklarının kapatılmasında, yeni istihdam olanakları oluşmasında, ulusal ve bölgesel ekonomik gelişmelere katkıda bulunmada önemlidir (Çoşkun, 2010). "Ülkeler daha fazla turizm gelirleri elde edebilmek için sahip oldukları turizm kaynaklarına uygun turizm faaliyetlerinin çeşitlemesine giderek, bir başka deyişle alternatif turizm faaliyetlerini geliştirerek, farklı istek ve ihtiyaçlara sahip turistleri kendine çekerek, turizm pazarından aldıkları payı artırmakta ve böylece ulusal ekonomilerinin gelişimine önemli bir katkı sağlamaktadırlar" (Öztürk \& Yazıcığlu, 2002). İnsanların taleplerine göre turizm faaliyetleri, yaz turizmi, sağlık ve termal turizmi, kış turizmi, yayla turizmi, mağara turizmi, av turizmi, kongre turizmi, dağcılık, gençlik turizmi, yat turizmi, inanç turizmi, akarsu-rafting turizmi, su altı dalış turizmi ve hava sporları turizmi olarak çeşitlenmiş olup, bunların hemen tamamının gerçekleştirilmesi konusunda Bingöl harika bir potansiyele sahiptir. Alternatif turizm geleneksel, klasik, kitle ve il turizminin olumsuz etkilerini en aza indirgemek ve sıradanlıktan arındırılmış yeni turistik ürünlerin bir araya getirilmesiyle ortaya çıkarılmış bir turizm çeşidi olup, turizm endüstrisinin temelini ve ticari bakışını değiştirerek kitle turizminin olumsuzluklarını da gidermede ön plandadır (Hacıoğlu \& Avcıkurt, 2008). Alternatif turizm içinde yer alan kırsal turizm, özellikle kırsal alanlarda kırsal kalkınma ve gelir getirme aracı olarak gerçekleştirilip, kültürel ve sosyal etkileşimi sağlayıcı bir araç olarak, gittikçe önemsenen bir turizm çeşididir. Bu tür turizm faaliyetlerinin gerçekleştirildiği çevrelerde halkın iş istihdamı artmakta ve konunun önemi daha da iyi anlaşılmaktadır. Alternatif turizm, turizm sektörüne olumlu bir ivme kazandırmasının yanında doğal kaynakları koruyarak kaliteli yaşanabilir bir çevre ve sürdürülebilir turizm faaliyetlerini destekler (Zoğal, 2014). Turizm faaliyetlerine katılanlar, fiziksel, duygusal, hissel, zihinsel ve ruhsal kapasitelerinin gelişmesine imkan sağlamak, huzur bulmak, rahatlamak ve deşarj olabilmek için kendilerine uygun yenilikler aramak üzere standart turist tipini geride bırakmaktadırlar. Aslında turizm türlerine olan talep turistlerin bireysel isteklerinden çok insanların içinde bulunduğu olumsuzluklardan da kaynaklanmaktadır. Yoğun iş temposu, çevre kirliliği, insanların sağlıklarını koruma hususundaki hassasiyetin azalması, doğal ortamlara ve doğal gıdalara özlem gibi gerekçelerle alternatif turizm türlerine olan talep artmaya devam etmektedir. Alternatif turizm türlerinden biri olan, kırsal turizm her geçen yıl önemini artırmakta, birçok ülkenin kırsal kalkınma politikalarında yer almakta ve kalkınma stratejilerinde desteklenmektedir (Fleischer \& Felsenstein 2000),). Kırsal turizm ülkemizde de özellikle büyük şehirlere yakın yerleşim birimlerinde ve doğal güzelliklerin yoğun olduğu bölgelerde giderek önemini artırarak yöreye olumlu yönde birçok katkısı (ekonomik, kültürel, sosyal v.b.) olmaktadır. Ayrıca bölgede ziyaretçiler için iyi kalitede bir deneyim sağlama, çevrenin kalitesini hem yerel halk hem de ziyaretçilere bağlı olarak koruma ve devam ettirme gibi avantajları da olmaktadır.

$\mathrm{Bu}$ çalışmada konuyla ilgili literatür verileri, gözlem, arazi çalışmaları ile alternatif turizm kavramı ve önemi anlatılmaya çalışılmış ve ele alınan konu çerçevesinde Bingöl'ün mevcut alternatif turizm potansiyeli değerlendirilerek alternatif turizm gelirlerinin il için önemi belirtilip, konuyla ilgili farkındalığın artması hedeflenmiştir.

\section{Materyal ve Metod}

Bu çalışmada konuyla ilgili literatür verileri, gözlem, arazi çalışmaları ve bilimsel çalışmalardan yararlanılmıştır. Bu çerçevede alternatif ve kırsal turizmin Bingöl'de ki durumu hem literatürden hem de mevcut durum gözlemlenerek değerlendirilmeye çalışılmıştır. 

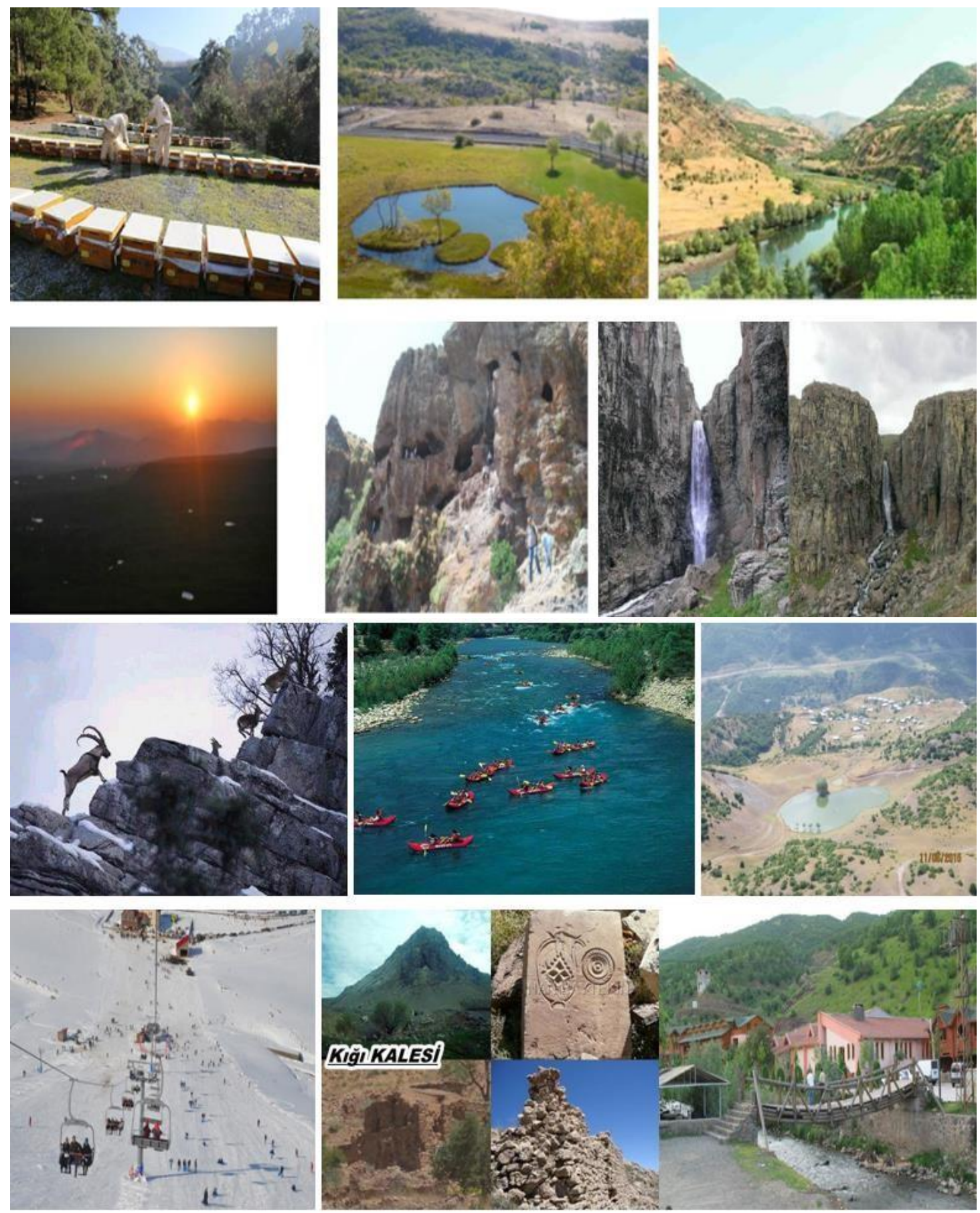

Şekil 1. Bingöl’ün Önemli Turizm Etkinlik ve Merkezlerinden Bazıları (10)

\section{Sonuç ve Tartıșma}

Turizm ekonomik, sosyal ve kültürel anlamda ülke, bölge ve il ekonomisinde önemli sonuçlar doğurmaktadır. Turizmin ekonomik etkilerini daha iyi anlamış ve turizm potansiyelini daha iyi kullanabilen ülkeler ve iller bu konudaki gelirlerini artırmaktadırlar. Turizm gelirleri dünyadaki birçok ülke ve bölge için önemini artırmış, bu durum turizm yatırımlarının da desteklenmesi ile birbirini izleyen döngüsel bir etkileşime yol açmıştır (Onur \& Çöz, 2004). Turizm türleri genelde şu şekildedir: kültür turizmi, sağlık turizmi, golf turizmi, yayla turizmi, gençlik turizmi, mağara turizmi, doğa turizmi, agro turizm, av turizmi, inanç turizmi, rafting turizmi, dağ ve kış turizmi, festival turizmi. Bunlara ek olarak botanik-flora turizmi, kuş gözlemciliği, yaban hayatı gözlemciliği, olta balıkçıllığı, bisiklet turizmi, balon turizmi, su altı - dalış turizmi, kamp - karavan turizmi, trekking, yamaç paraşütü, ekolojik tarım ve çiftlik turizmi, kongre turizmi gibi turizmin bir çok çeşidi bulunmaktadır. Bu turizm türlerinin birçoğunun 
Bingöl'de uygulama alanı bulunmaktadır. Doğal ortamlara ve yaşama duyulan ilgi ve ihtiyaç, kırsal turizmin esasını oluşturmaktadır. Hedeflenen alanlarda yapılacak kırsal turizm aktivitelerini yörenin özgün değerlerinden yararlanarak zenginleştirmek mümkündür. Bozulmamış, doğallığını kaybetmemiş doğal çevrelerde ve doğa harikalarının bulunduğu kırsal yörelerde gezmeyi ve buraları görmeyi arzu eden ziyaretçiler otantik atmosferdeki etkinlikleri tercih etmekte ve sonuçta bedensel ve ruhsal olarak da rahatlamaktadırlar. Konaklama hizmetleri için köylünün günlük yaşamını sürdürdüğü evler, pansiyonlar, kampingler veya kırsal tatil köyleri ilgi görmektedir. Kültür gezileri, yakın çevrede doğa yürüyüşleri, yerel el sanatları ile yemeklerin tanıtımı, hayvancılık, tarım gibi etkinlikler ve/veya hizmetler ziyaretçilerin ilgisini artırmaktadırlar (Zeyrek, 2008). Ulaşımının kolay ve ekonomikliği, yöre halkının etkileşime açık olması, misafirperverliği, bitki örtüsü zenginliği (Kilic \& Yıldırımlı, 2014; Yıldırımlı \& Kilic 2014) yoğun arıcılık faaliyetleri, çeşitli doğa turizmi (Yayla-flora-kış-akarsu-av-mağara turizm alanlarının olması, zengin biyoçeşitliliğe sahip olması, tarihi ve kültürel değerlerinin olması, yaban hayatı gözlemciliği ve doğa yürüyüşü) etkinliklerinin olması Bingöl'ün bu konudaki önemini göstermektedir. Turizm gelirleri, ülkelerin ekonomideki yerini ve önemini tespit etmek için belirlenen bir gerekçede katma değer sağlamaktadır. Turizm sektöründe risk yaratan yoğun rekabetten başarıyla çıkabilmek için ülkeler, mevcut alternatif kaynaklarını rasyonel ve akılcı bir şekilde kullanmak, ekonomik, sosyal ve kültürel kazanımlarını artırmak gerekliliğinden ötürü alternatif turizme gereken önemi vermek durumundadırlar. Böylelikle rakip ülkelerle rekabet gücü artar iç ve dış konjonktüre olan bağımlılık azalır. Ülkemiz ve Bingöl'de kullanılabilecek alternatif turizm kaynaklarını belirleyerek ve geliştirerek turistlerin beklentilerini karşlayabilecek yeni turizm çeşitlilikleri ile sektöre ivme kazandırmalıdır. Ülke, bölge ve illerimizin turistik çekiciliklerini ortaya koyarak bunları bütünleştirip yeni alternatif turizm türleri oluşturarak sürdürülebilirlik çerçevesinde turizm sektörünün devamı sağlanmalıdır. Turizmde bütünleşmeye çok önemli bir gereklilikle bakılmakta olup, turizm türleri arasındaki bütünleşme, bir turizm faaliyeti esnasında diğer turizm çeşitlerinin de aynı süreçte bir arada gerçekleşmesinin sağlanmasıdır (Baykal \& Emekli, 2010). Bingöl sahip olduğu doğal tarihi zenginlikler, buna bağlı turizm olanakları ve alternatif turizm çeşitliliği açısından oldukça zengin bir ildir. Ancak Bingöl bu potansiyel değere rağmen turizm hareketliliği gelirlerinden daha az pay almaktadır. Bu sonucun çeşitli sebepleri olmakla beraber en önemlisi elde bulunan kaynakların rasyonel ve akılcı kullanılamamasıdır. Dünyada birçok ülke alternatif turizm türleri az olmasına rağmen elinde bulunan kıt kaynakları verimli bir şekilde değerlendirerek turizmden büyük gelirler elde etmektedirler. Turizmin ülke çapında gelişmesi, bölgeler ile iller arasındaki gelişmişlik farkının azaltılması, turizm gelirlerinin artması ve buna bağlı olarak iç göçlerin önlenebilmesi alternatif turizm türlerine yönelmek suretiyle sağlanabilir. Yerel halk ve turizm sektöründe çalışanların eğitilmesi, turizm bilincinin oluşturulması, yöre halkının turizme sıcak bakmasının sağlanması böylelikle halkın turizm faaliyetlerinde daha fazla yer almasını sağlayacaktır. Alternatif turizm türleri fuar ve tanıtım günlerinin devlet eliyle birlikte, üniversiteler, özel sektör ve sivil toplum kuruluşları ile yaygınlaştırılması ve ulaşım imkanlarının kolaylaştırılması sektöre destek vermek açısından önem taşımaktadır. Kıyı bölgelerinde olduğu gibi kitle turizmine hizmet veren konaklama tesisleri iç bölgelerde de fazlalaştırılmalı ve böylece ulusal ve yerel yatırımcıların turizm sektöründe daha aktif şekilde yer almaları sağlanır. Alternatif turizm türleri kapsamında; tarihi ve kültürel değerler korunarak zenginleştirilmeli turistlere doğal kaynaklar ve zengin kültürel değerler sunularak turist memnuniyeti sağlanmalıdır. Geliştirilecek alternatif yörelerin tanıtım ve pazarlama faaliyetleri de etkin bir şekilde yapılmalıdır. Alt yapı sorunlarını tamamlamış, hizmet kalite standardı yüksek turizm işletmelerine sahip, belirli bir prestij kazanmış, rakiplerini geride bırakacak alternatif turizm türleri olan ülkelerin ve illerin turizm gelirlerinden daha fazla gelir elde etmesi kaçınılmazdır. Çeşitli olumsuzluklardan dolayı bölge ile ildeki turizm gelirinin azalması cari işlemler açığının artmasına, istihdamın ve ekonomik büyümenin azalmasına neden olabilecektir. Dolayısıyla, ildeki ziyaretçi sayısındaki artışı sağlayabilmek için, öncelikle ekonomik ve siyasi problemlerin oluşmasını engelleyici önlemlerin alınması ve ilin turizm potansiyelinin tanıtımının daha iyi yapılması gereklidir. Bunların yanında, turizm yatırımlarına gereken önem verilmeli, verilen hizmetlerin kalitesi artırılmalı ve ulaşım olanakları genişletilmelidir. Alternatif ve kırsal turizm faaliyetleri arttıkça ve bunlar sürdürülebilir tarzda devam ettikçe, Bingöl'ün kırsal turizm açısından zenginliği daha da belirginleşecek ve bu durum yöre halkının daha da kalkınmasını sağlayacaktır. Ayrıca kırsal alanlarda gerçekleştirilen akarsu sporları (kano-rafting-nehir kayağı), doğa yürüyüşü, dağcılık, atlı doğa yürüyüşü, dağ bisikleti, kültür varlıkları ve mağara ziyaretleri, sportif olta balıkçılığı, yaban hayatı ve kuş gözlemciliği, bitki inceleme ve foto safari vb. gibi turizm faaliyetlerinin sürekliliği, bu alanların sahip olduğu özgün değerlerin korunması ve sürdürülebilir kullanımı ile sağlanmaktadır. $\mathrm{Bu}$ nedenle, doğal çevrenin korunmasına yönelik uygulamalar artırılmalı, tarımsal ürün çeşitliliği, doğal kaynaklar, tarihi ve kültürel değerler ile doğal peyzaj özelliklerinin kırsal alanlarda gerçekleştirilen turizm aktiviteleri için önemli bir kaynak olduğu unutulmamalı, bu kaynakların kırsal alanlarda ek gelir ve istihdam olanakları 
sağlayabilmesi için teşvikler artırılmalıdır. Bingöl'ün uluslararası ve ulusal bir turizm merkezi haline gelebilmesi için, tanıtım ve pazarlama açısından teknik ve finansal desteğe ve iyi bir planlama sistemine ihtiyaç olup, gençlik kampları, yaz okulları, gençlik festivalleri ve okul gezileri düzenlenmeli ve konuyla ilgili projeler hazırlanarak uygulamaya geçilmelidir.

Sonuç olarak Bingöl ilinin sahip olduğu doğal, kültürel ve tarihsel çekiciliklerin en iyi şekilde değerlendirilerek ve alternatif turizm alanları geliştirilerek yörenin ekonomik gelişimine katkı sağlanabilmesi amacıyla, turizm sektörü daha da aktifleştirilmelidir. Bu nedenle başta yerel paydaşlar olmak üzere tüm kamu ve özel sektör kuruluşlarının yapacağı kısa, orta ve uzun vadeli turizm planlama çalışmaları ile Bingöl ilinde turizm sektörü daha da aktif hale getirilebilir.

\section{Kaynaklar}

Akar, H. ve Karamanbüyük, E. (2006). Turizm sektörü.www.deu.edu.tr/userweb (Erişim Tarihi: 14.11.2015).

Çoşkun, N. (2010). Türkiye'de turizm politikaları ve turizm sektörü üzerindeki etkileri. Uzmanlık tezi, Kültür ve Turizm Bakanlığı Kütüphaneler ve Yayımlar Genel Müdürlüğü

Öztürk, Y. ve Yazıcıoğlu, İ. (2002). Gelişmekte olan ülkeler için alternatif turizm faaliyetleri üzerine teorik bir çalışma. http://ttefdergi.gazi.edu.tr/makaleler/2002/Sayı 2. (Erişim Tarihi: 9.10.2015).

Hacıŏlu, N. ve Avcıkurt, T.C. (2008). Turistik Ürün Çeşitlendirmesi Ve Alternatif Turizm.

Ankara : Nobel Yayınları Dağıtım. Zoğal, V. (2014). Seferihisar'da Turistik Ürün Çeşitlendirmesi

ve Bütünleşik Turizm Olanakları.

VII. Lisansüstü Turizm Öğrencileri Araştırma Kongresi. Kuşadası / Aydın

Fleischer, A. and Felsenstein, A. (2000), "Support For Rural Tourısm Does it Make a Difference?", Annals of Tourism Research, 27 (4): 1007-1024.

Onur, K. ve Çöz, O. (2004). Turizm Uydu Hesapları. Dokuz Eylül Üniversitesi Sosyal Bilimler Enstitüsü Dergisi, VI, 1.

Zeyrek, A.N. (2008). "Besni'de Alternatif Turizm Potansiyeli”, Gaziantep Üniversitesi Sosyal Bilimler Dergisi, 7(2): 451-466.

Kilic, O. ve Yıldırımlı, Ş. (2014). Bingöl Merkez Dikme yaylası ve çevresinin fulorası. Ot Sistematik Botanik Dergisi, 21 (1): 69-126.

Yıldırımlı, Ş. ve Kilic, O. (2014). Sivas ve Bingöl illerinden üç yeni tür. Ot Sistematik Botanik Dergisi, 21 (2): 1-14.

Baykal, F. ve Emekli, G. (2010). Sürdürülebilir Turizm Yaklaşımıyla Dikili ve Bergama'yı Bütünleştirme Potansiyeli. Tübitak 1002 Hızlı Destek Programı. Proje No: 109K323 Yayınlanmış Proje Raporu. Bergama: Bergama Belediyesi Kültür Yayınları. 